\title{
Controlled Release Modeling of Urea from Chitosan Microspheres: Effect of Stirring Speed and Volume Ratio of Continuous to Dispersed Phase
}

\author{
Jayanudin ${ }^{1,2,3, *}$, Indar Kustiningsih ${ }^{1,4}$, Retno S. D. Lestari ${ }^{1}$, Rozak Bahaudin ${ }^{4}$, \\ Dandi Irwanto 4
}

1 Chemical Engineering Department, Universitas Sultan Ageng Tirtayasa, Jl. Jenderal Sudirman km.3 Cilegon-Indonesia 42435; jayanudin@untirta.ac.id (J.); rsdlestari@untirta.ac.id (R.S.D.L.);

2 Applied Biomaterial and Product Engineering Laboratory, Universitas Sultan Ageng Tirtayasa, Jl. Jenderal Sudirman km.3, Cilegon 42435, Indonesia; jayanudin@untirta.ac.id (J.);

3 Center of Excellence Local Food Innovation, Universitas Sultan Ageng Tirtayasa, Jl. Raya Palka Km 3 Sindangsari, Pabuaran, Kab. Serang-Indonesia; jayanudin@untirta.ac.id (J.);

4 Master of Chemical Engineering, Universitas Sultan Ageng Tirtayasa, Jl. Raya Jakarta Km 4 Pakupatan, Serang 42118, Indonesia; indar.kustiningsih@untirta.ac.id (I.K.); rozaks22019@gmail.com (R.B.); dandi.sleman@gmail.com (D.I.);

* Correspondence: jayanudin@untirta.ac.id (J.);

Scopus Author ID 56862336000

Received: 13.10.2021; Revised: 10.11.2021; Accepted: 14.11.2021; Published: 25.11.2021

\begin{abstract}
The purpose of this study was to determine the release kinetics and diffusion coefficient of chitosan microspheres containing urea based on changes in the stirring speed and the volume ratio of the continuous to dispersed phase (CP/DP). Chitosan microspheres filled with urea were prepared using the emulsion cross-linking method. The initial stage of this method has formed an emulsion then slowly dripped with glutaraldehyde saturated toluene as a crosslinker. Urea-loaded chitosan microspheres were washed and dried and then tested for release in an aqueous medium. The calculated cumulative release was used to determine the release kinetics and diffusion coefficient of chitosan microspheres. The appropriate release kinetics model was Simple Power Law with the Burst Effect because it produces an $\mathrm{R}^{2}$ value of 0.99 . The mechanism of urea release from chitosan microspheres is Case II the transport mechanism represents pure relaxation behavior. Determination of the diffusion coefficient values from $1,180 \times 10^{-14}$ up to $1,433 \times 10^{-14} \mathrm{~cm}^{2} / \mathrm{sec}$.
\end{abstract}

Keywords: release kinetics; urea; diffusion coefficient; emulsion cross-linking.

(C) 2021 by the authors. This article is an open-access article distributed under the terms and conditions of the Creative Commons Attribution (CC BY) license (https://creativecommons.org/licenses/by/4.0/).

\section{Introduction}

Urea fertilizer is one of the most widely used sources of nutrients for plant growth because of cheap. The nitrogen content of urea is the highest of all fertilizers, which is about $46 \%[1,2]$. Conventional urea has the disadvantage that it is easily soluble in water even though the plant's absorption capacity for its nutritional needs is less than $35 \%[2,3]$. Nitrogen that is not absorbed will be abundant in the environment and can cause nutrient imbalances in the soil and can cause the greenhouse effect $[3,4]$.

Widely developed solutions are wrapping urea with a polymer/biopolymer to regulate the controlled release or mixing the urea with other materials like a composite for slow release. This form of fertilizer can increase the efficiency of nutrient absorption by plants. Methods for 
the preparation of urea controlled release have been developed by many researchers. The emulsion cross-linking method for urea-loaded chitosan microspheres preparation was previously developed by Jayanudin et al. [5]. The release of urea from chitosan microspheres depends on the strength of the microsphere walls. The denser the walls of the microspheres, the less urea is released. The urea release behavior of chitosan microspheres was determined by the release kinetics to determine the achievement of the desired urea concentration. Analysis of the wall strength of chitosan microspheres determined by the diffusion coefficient. The release kinetics model and determining the diffusion coefficient refers to the research that has been reported by Malekjani [6]; Beig et al. [7,8]; Siepmann and Siepmann [9]. Cumulative release data of urea fertilizer from chitosan microspheres were taken, and research data was reported by Jayanudin et al. [5]. The purpose of this study was to determine the release kinetics and diffusion coefficient due to the influence of stirring speed and volume ratio of CP/DP.

\section{Materials and Methods}

\subsection{Materials.}

This research uses materials such as urea from PT. PUSRI, pro-analyst grade glutaraldehyde from Merck with a concentration of $25 \%(\mathrm{v} / \mathrm{v})$, chitosan produced by PT. Biotech Surindo with DD $=87.2 \%$ and viscosity $37.10 \mathrm{cps}$, toluene, petroleum ether, and hexane are all technical grades obtained from CV. Tri Jaya Dinamika, vegetable oil produced by PT. Sarwana Nusantara, and glacial acetic acid from Merck.

\subsection{Preparation of urea-loaded chitosan microspheres.}

Preparation of urea-loaded chitosan microsphere refers to the study reported by Jayanudin et al. [5]. The first step was chitosan dissolved with $1 \%(\mathrm{v} / \mathrm{v})$ glacial acetic acid to get a concentration of $4 \%(\mathrm{w} / \mathrm{v})$ chitosan. Glutaraldehyde saturated toluene (GST) as a crosslinker was prepared using the same method from Jayanudin et al. [5]. Urea was dissolved in a chitosan solution (dispersed phase) and then added in vegetable oil (continuous phase) with a CP/DP ratio of 4:1, 6:1, and 8:1, then immediately stirred with a stirring speed of 10,000 $\mathrm{rpm}, 15,000 \mathrm{rpm}$, and 20,000 rpm to form an emulsion. GST was dropwise into the emulsion for the cross-linking process. The mixture was continuously stirred for the solidification process of chitosan microspheres. The last stage was chitosan microspheres filtered, washed, and dried. Urea release test from chitosan microspheres using water medium and analyzed using Nessel reagent to determine Nitrogen concentration.

\subsection{Cumulative release analysis of urea from chitosan microspheres.}

$0.2 \mathrm{~g}$ of chitosan microspheres filled with urea were immersed in $50 \mathrm{~mL}$ of water for 1 , $3,7,14,21$, and 30 days. The cumulative release analysis was carried out by determining the nitrogen content based on the immersion time using Nessler's reagent.

\subsection{Release kinetics model.}

The release kinetics model used in this study refers to the research reported by Malekjani and Jafari [6]; Beig et al. [7]; Beig et al. [8]. The release kinetics model was shown in equations 1-4. 
Peppas-Sahlin model

$\frac{\mathrm{M}_{\mathrm{t}}}{\mathrm{M}_{\infty}}=\mathrm{k}_{1} \mathrm{t}^{\mathrm{m}}+\mathrm{k}_{2} \mathrm{t}^{2 \mathrm{~m}}$

Sinclair and Peppas model

$\frac{\mathrm{M}_{\mathrm{t}}}{\mathrm{M}_{\infty}}=\mathrm{at} \mathrm{t}^{\mathrm{b}}$

Modified hyperbola formula

$\frac{\mathrm{M}_{\mathrm{t}}}{\mathrm{M}_{\infty}}=\frac{\text { at }}{1+b t}$

Modification of power law with burst effect

$\frac{\mathrm{M}_{\mathrm{t}}}{\mathrm{M}_{\infty}}=\mathrm{kt}^{\mathrm{n}}+b$

where $\frac{\mathrm{M}_{\mathrm{t}}}{\mathrm{M}_{\infty}}$ is cumulative release, $\mathrm{k}_{1}, \mathrm{k}_{2}, a$, and $b$ are release kinetics constants, and $\mathrm{t}$ is release time.

\subsection{Determination of diffusion coefficient.}

The diffusion coefficient was determined using the equation formulated by Siepmann and Siepmann $[9,10]$ for reservoir systems with non-constant activity sources, as shown in equation 5.

$$
\frac{\mathrm{M}_{\mathrm{t}}}{\mathrm{M}_{\infty}}=1-\exp \left(-\frac{3 R_{0} D K t}{R_{i}^{2} R_{0}-R_{i}^{3}}\right)
$$

where $\frac{\mathrm{M}_{\mathrm{t}}}{\mathrm{M}_{\infty}}$ is cumulative release, $R_{0}$ is the outer radius, $R_{i}$ is the inner radius, $\mathrm{D}$ is diffusion coefficient, $\mathrm{K}$ is constant, and $\mathrm{t}$ is release time. To determine using the equation $R_{i}=R_{0}-\delta$, where is the wall thickness of chitosan microspheres is determined by the equation reported by Jayanudin et al. [11].

\section{Results and Discussion}

\subsection{Release kinetics.}

Cumulative release and diameter size data of chitosan microspheres taken from the study have been reported by Jayanudin et al. [5]. The release kinetics model used in this study was different from Jayanudin et al. [5], as shown in equations $1-4$.

\subsubsection{Determination of the release kinetics based on the change in stirring speed.}

The kinetic model used in the study that has been reported by Jayanudin et al. [5] was the Higuchi and Korsmeyer-Peppas model, while this study used a different release kinetics model as shown in Equations 1 - 4. Figure 1 shows a comparison of cumulative release from experimental and calculation data using the kinetic release model.

The urea release kinetics model of chitosan microspheres was used to reveal the mechanism of urea release in the dissolution medium [12]. The mechanism of release of fertilizer from the carrier is the same as the release of drugs such as dissolution, erosion, diffusion, adsorption/desorption, and swelling [12,13]. The Sinclair and Peppas models reveal a diffusion mechanism of release through non-swelling devices (slabs, cylinders, and spheres). The modified hyperbola formula shows the release is first order at a low $\mathrm{t}$ value and decreases to zero-order when t increases [8]. The Peppas-Sahlin model explains two release mechanisms, 
where the first term is the Fickian contribution and the second term is the case-II relaxation contribution. The coefficient $m$ is the pure Fickian diffusion exponent for any set of geometric shapes that exhibits controlled release [6]. The modified Power-law model with burst effect shows a modification of Power-law or Korsmeyer-Peppas model by adding constant b, which indicates burst effect. Comparison of research data with calculation data using the release kinetics model (Equation 1-4) was shown in Figure 1.
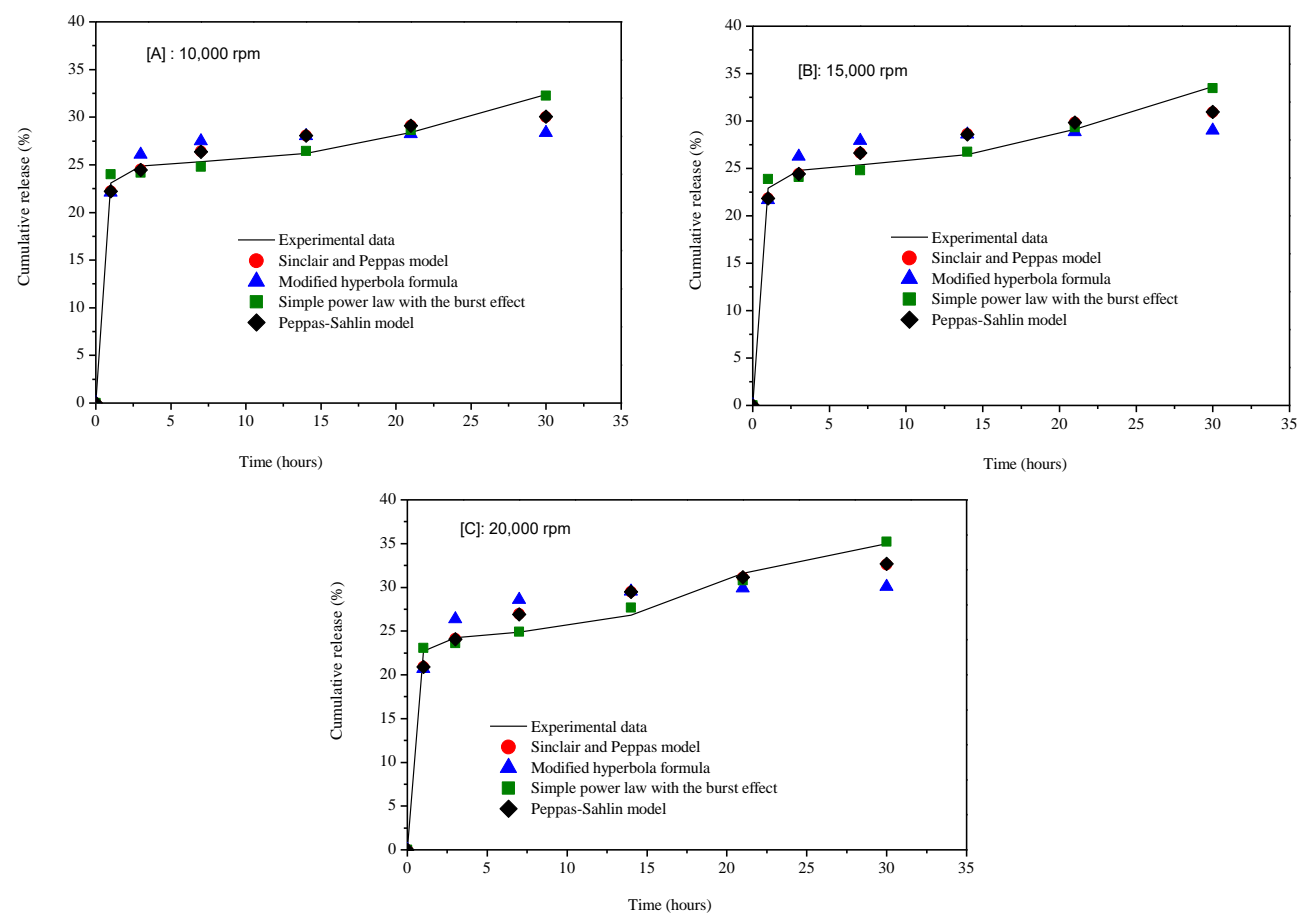

Figure 1. Comparison of experimental and calculated data using a release kinetics model based on changes in stirring speed [A]. 10,000 rpm, [B]. 15,000 rpm, and [C]. 20,000rpm

Figure 1 shows that the change in stirring speed affects the size of the chitosan microspheres and could directly affect the cumulative release of urea. This was because increasing the stirring speed decreases the diameter size of the chitosan microspheres. The smaller the size could increase the contact area between the chitosan microspheres and the release medium so that the cumulative release of urea from the chitosan microspheres increases [5].

The appropriate release kinetics model based on comparing the cumulative release of the experimental and calculations data using the release kinetics model was determined with the best fitting based on the $\mathrm{R}^{2}$ value. Figure 1 shows the best fitting is a modified power-law model with a burst effect with an $\mathrm{R}^{2}$ value for all variables $(10,000 \mathrm{rpm}, 15,000 \mathrm{rpm}$, and $20,000 \mathrm{rpm}$ ) of 0.99 . Releases with burst effects were identical to purely diffusion-controlled kinetics. The value of $\mathrm{n}$ in this model indicates the release mechanism that occurs in the release of urea from chitosan microspheres. The resulting $n$ values from this model were $n=1.59$ for [A] 10,000 rpm, $n=1.56$ for [B] 15,000 rpm, and $n=1.25$ for [C] 20,000 rpm. The value of $n$ $>1$ indicates super case II transport [14].

3.1.2. Determination of the release kinetics based on the change in the volume ratio of the continuous to dispersed phase (CP/DP).

Changes in the volume ratio between CP/DP had an effect on the cumulative release of urea from chitosan microspheres. An increase in the volume ratio of CP/DP, decreases the 
cumulative release of urea and vice versa. This was due to the chitosan microspheres produced using a large continuous phase volume resulting in harder microspheres due to a faster solidification process and reduced microsphere porosity [5]. Figure 2 shows a comparison between the cumulative release of the experimental and the calculation data results with the release kinetics model.

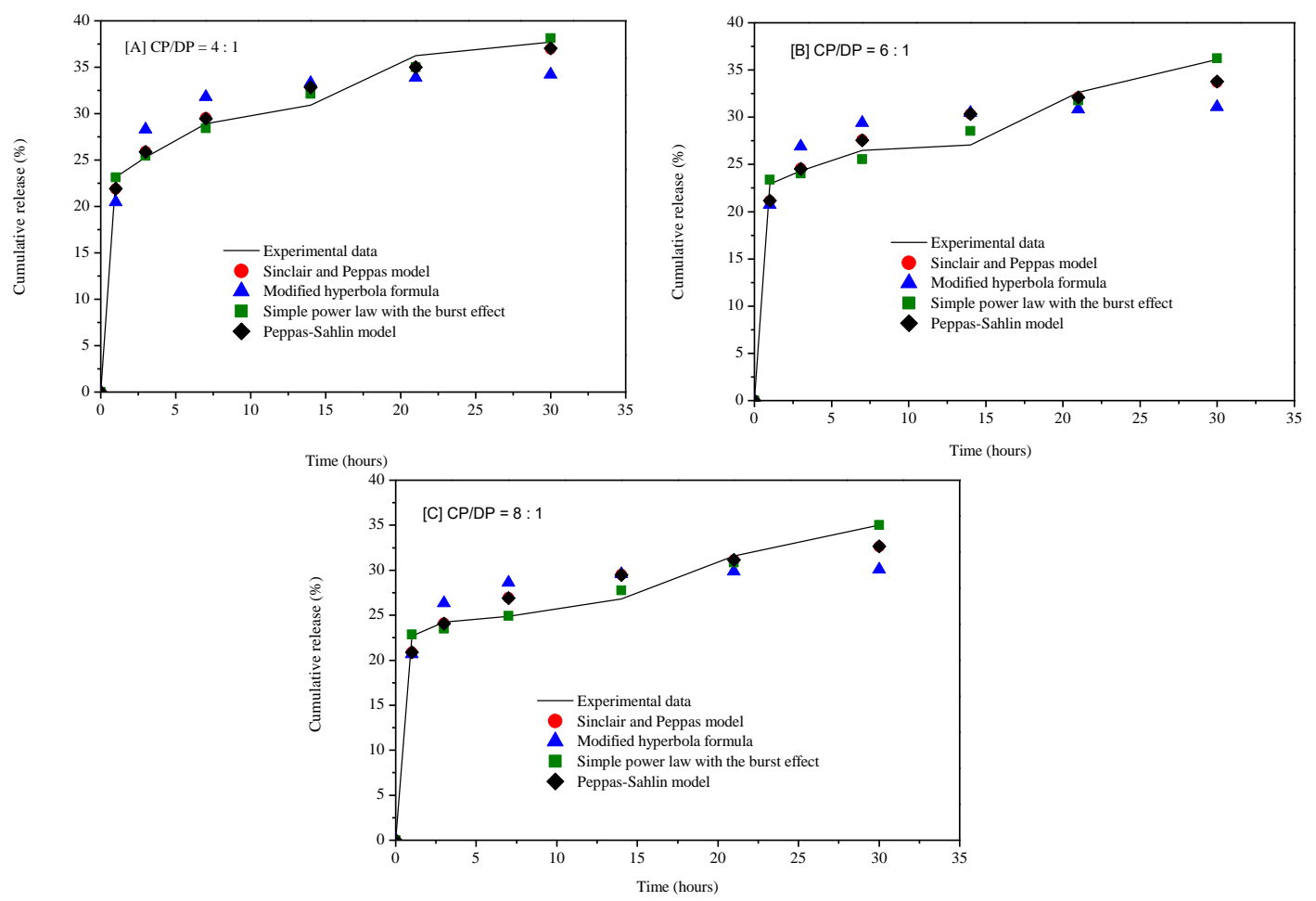

Figure 2. Comparison of experimental and calculated data using a release kinetics model based on changes in the volume ratio of CP/DP [A] $4: 1,[$ B] $6: 1$, and [C] $8: 1$.

Table 1. The kinetic constant of urea release from chitosan microspheres

\begin{tabular}{|c|c|c|c|c|c|c|c|}
\hline \multirow{2}{*}{ Variable } & \multicolumn{4}{|c|}{ Peppas-Sahlin model } & \multicolumn{3}{|c|}{ Sinclair and Peppas } \\
\hline & $\mathbf{m}$ & $\mathbf{k}_{1}$ & $\mathbf{k}_{2}$ & $\mathbf{R}^{2}$ & $\mathbf{a}$ & b & $\mathbf{R}^{2}$ \\
\hline \multicolumn{8}{|c|}{ Volume ratio between continuous phase and dispersed phase } \\
\hline $4: 1$ & 0.116 & 15.571 & 6.337 & 0.99 & 21.865 & 0.154 & 0.99 \\
\hline $6: 1$ & 0.103 & 14.992 & 6.156 & 0.98 & 21.142 & 0.137 & 0.98 \\
\hline $8: 1$ & 0.099 & 14.759 & 6.123 & 0.98 & 20.882 & 0.131 & 0.98 \\
\hline \multicolumn{8}{|c|}{ Stirring speed (rpm) } \\
\hline 10,000 & 0.067 & 15.460 & 6.765 & 0.99 & 22.225 & 0.088 & 0.99 \\
\hline 15,000 & 0.077 & 15.275 & 6.551 & 0.98 & 21.825 & 0.103 & 0.98 \\
\hline 20,000 & 0.099 & 14.762 & 6.120 & 0.98 & 20.882 & 0.131 & 0.98 \\
\hline \multirow[t]{2}{*}{ Variable } & \multicolumn{3}{|c|}{ Modified hyperbola formula } & \multicolumn{4}{|c|}{$\begin{array}{c}\text { Simple Power Law with the Burst } \\
\text { Effect }\end{array}$} \\
\hline & $\mathbf{a}$ & b & $\mathbf{R}^{2}$ & $\mathbf{k}$ & b & n & $\mathbf{R}^{2}$ \\
\hline \multicolumn{8}{|c|}{ Volume ratio between continuous phase and dispersed phase } \\
\hline $4: 1$ & 49.189 & 1.405 & 0.97 & 2.861 & 20.273 & 0.538 & 0.99 \\
\hline $6: 1$ & 59.953 & 1.897 & 0.96 & 0.253 & 23.132 & 1.161 & 0.99 \\
\hline $8: 1$ & 63.795 & 2.088 & 0.96 & 0.247 & 22.617 & 1.151 & 0.99 \\
\hline \multicolumn{8}{|c|}{ Stirring speed (rpm) } \\
\hline 10,000 & 96.860 & 3.383 & 0.98 & 0.037 & 23.961 & 1.588 & 0.99 \\
\hline 15,000 & 82.976 & 2.830 & 0.97 & 0.048 & 23.806 & 1.557 & 0.99 \\
\hline 20,000 & 63.795 & 2.088 & 0.96 & 0.176 & 22.896 & 1.249 & 0.99 \\
\hline
\end{tabular}

Comparison of experimental and calculation data as shown in Figure 1 produces the best fitting, namely the modified Power-law model with a burst effect. The highest $\mathrm{R}^{2}$ value was owned by this model, with a value of 0.99 . The mechanism of urea release from chitosan microspheres was determined by the value of $\mathrm{n}$ in this modified Power-law model. The value of $n$ for CP/DP $(4: 1)$ was 0.54 , CP/DP $(6: 1)$ was 1.16 , and CP/DP $(8: 1)$ was 1.15 . The value 
of $\mathrm{n}>1$ indicates, according to Case II transport mechanism represents pure relaxation behavior [9]. Meanwhile, the value of $\mathrm{n}$ is $0.43<\mathrm{n}<0.83$, including anomalous transport or non-Fickian transport, which was defined as having two mechanisms, namely diffusion and swelling (relaxation of polymer chains). The values of the release kinetics constants and $\mathrm{R}^{2}$ for each variable of this study are shown in Table 1.

The release kinetic constants in Table 1 show that the appropriate release kinetics model was Simple Power Law with the Burst Effect because $\mathrm{R}^{2}$ in all variables is 0.99 . Figures 1 and 2 also show that the Simple Power Law with the Burst Effect model is good fitting.

\subsection{Determination of the diffusion coefficient.}

The mathematical model used to determine the diffusion coefficient was based on the equation compiled by Siepman and Siepman [9,10] for reservoir systems with non-constant activity sources. This mathematical model applies Fick's law of diffusion, where the nucleus exits the microsphere after the medium (water) penetrates the system, dissolving the microsphere nucleus, then the dissolved nucleus diffuses out of the system through the surrounding membrane. The surrounding bulk fluid provides perfect reservoir conditions. Furthermore, there was no excess of the active ingredient in the nucleus, so the released nuclear molecules were not replaced, and the concentration of the core material on the inner membrane surface decreased with time. This was called a "reservoir system with non-constant sources of activity" [6,9]. Determining the diffusion coefficient serves to determine the speed of the diffusion rate. Table 2 contains a collection of data on the diffusion coefficient resulting from calculations using equation 5 .

Table 2. Diffusion coefficient of chitosan microspheres filled urea.

$$
\begin{array}{l|l}
\text { Variable } & \text { Diffusion coefficient }(\mathrm{D})\left(\mathrm{cm}^{2} / \mathrm{sec}\right)
\end{array}
$$

\begin{tabular}{c|c}
\hline \multicolumn{2}{c}{ Volume ratio between the continuous phase and dispersed phase } \\
\hline $4: 1$ & $1.433 \times 10^{-14}$ \\
\hline $6: 1$ & $1.233 \times 10^{-14}$ \\
\hline $8: 1$ & $1.180 \times 10^{-14}$ \\
\hline Stirring speed (rpm) & $1.308 \times 10^{-14}$ \\
\hline 10,000 & $1.270 \times 10^{-14}$ \\
\hline 15,000 & $1.197 \times 10^{-14}$
\end{tabular}

Table 2 shows that increasing the stirring speed decreases the value of the diffusion coefficient, as well as the volume ratio of CP/DP where increasing the CP/DP volume ratio decreases the diffusion coefficient value. Besides being influenced by the concentration of the wall material because it was related to the density of the walls of the microspheres, the rate of diffusion was also influenced by the diffusion coefficient. Increasing the diffusion coefficient increased the rate of diffusion. The cumulative release of urea from chitosan microspheres reported by Jayanudin et al. [5] showed that the release time at 14, 21, and 30 days was higher than the stirring speed of 10,000 rpm and 15,000 rpm. The value of the diffusion coefficient of stirring at 20,000 rpm should also be greater than that of 10,000 rpm and 15,000 rpm.

This possibility occurs because the cumulative release value of the stirring speed of $20,000 \mathrm{rpm}$ at 1,3, and 7 days was greater than the speed of 10,000 rpm and 15,000 rpm. This was possible at 20,000 rpm having a smaller diffusion coefficient compared to $10,000 \mathrm{rpm}$ and $15,000 \mathrm{rpm}$. 


\section{Conclusions}

The urea release kinetics from chitosan microspheres was determined using the PeppasSahlin model, Sinclair and Peppas model, modified hyperbola formula, and modified powerlaw with burst effect. The model with a good fit is Simple Power Law with the burst effect with an $R^{2}$ value of 0.99 for all variables. The value obtained is $n>1$, which indicates that the transport mechanism represents pure relaxation behavior according to Case II. The value of the diffusion coefficient is directly proportional to the rate of diffusion; the greater the diffusion coefficient, the rate of diffusion also increases. The value of the diffusion coefficient obtained starts from $1.180 \times 10^{-14}$ to $1.433 \times 10^{-14} \mathrm{~cm}^{2} / \mathrm{sec}$. The urea release mechanism from chitosan microspheres is a case II transport mechanism representing a pure relaxation behavior.

\section{Funding}

This research received no external funding.

\section{Acknowledgments}

Authors would like to say thank you to the Lembaga Penelitian dan Pengabdian Kepada Masyarakat (LPPM)-Universitas Sultan Ageng Tirtayasa for the opportunity to obtain an internal basic research grant in 2020. We also thank the Department of Chemical Engineering, Universitas Sultan Ageng Tirtayasa, for all the facilities provided so that this research has been a success.

\section{Conflicts of Interest}

The authors declare no conflict of interest.

\section{References}

1. Beig, B.; Niazi, M,B,K.; Jahan, Z.; Hussain, A.; Zia, M,H.; Mehran, M,T. Coating materials for slow release of nitrogen from urea fertilizer: a review, J. Plant Nutr. 2020, 43, 1510-1533. https://doi.org/10.1080/01904167.2020.1744647.

2. Chen, Z.; Wang, Q.; Ma, J.; Zou, P.; Jiang, L. Impact of controlled-release urea on rice yield, nitrogen use efficiency and soil fertility in a single rice cropping system. Sci. Rep. 2020, 10, 1-10. http://dx.doi.org/10.1038/s41598-020-67110-6.

3. Olaleye, A.; Peak, D.; Shorunke, A.; Dhillon, G.; Oyedele, D.; Adebooye, O.; Akponikpe, P,B,I. Effect of manure and urea fertilization on yield, carbon speciation and greenhouse gas emissions from vegetable production systems of Nigeria and republic of Benin: A phytotron study. Agronomy 2020, 10, 1-20, http://dx.doi.org/10.3390/agronomy 10030400.

4. Bortoletto-Santos, R.; Guimarães, G.G.F.; Junior, V.R.; Da Cruz, D.F.; Polito, W.L.; Ribeiro, C. Biodegradable oil-based polymeric coatings on urea fertilizer: $\mathrm{N}$ release kinetic transformations of urea in soil, Sci. Agric. 2020, 77, 1-9, https://doi.org/10.1590/1678-992x-2018-0033.

5. Jayanudin; Lestari, R.S.D.; Kustiningsih, I.; Irawanto, D.; Bahaudin, R.; Wardana, R.L.A.; Muhammad, F.; Suyuti, M.; Luthfi, M. Preparation of chitosan microspheres as carrier material to controlled release of urea fertilizer, South African J. Chem. Eng., 2021, 38, 70-77, https://doi.org/10.1016/j.sajce.2021.08.005.

6. Malekjani, N.; Jafari, S,M. Modeling the release of food bioactive ingredients from carriers/nanocarriers by the empirical, semiempirical, and mechanistic models. Compr. Rev. Food Sci. Food Saf. 2020, 20, 3-47, https://doi.org/10.1111/1541-4337.12660.

7. Beig, B.; Niazi, M,B,K.; Jahan, Z.; Pervaiz, E.; Shah, G,A.; Ul Haq, M.; Zafar, M,I.; Zia, M. Slow-release urea prills developed using organic and inorganic blends in fluidized bed coater and their effect on Spinach productivity. Sustain., 2020, 12, 1-16, http://doi.org/10.3390/SU12155944. 
8. Beig, B.; Niazi, M,B,K.; Jahan, Z.; Kakar, S,J.; Shah, G,A.; Shahid, M.; Zia, M.; Ul Haq, Rashid, M.I. Biodegradable polymer coated granular urea slows down $\mathrm{n}$ release kinetics and improves spinach productivity. Polymers, 2020, 12, 1-19, http://doi.org/10.3390/polym12112623.

9. Siepmann, J.; Siepmann, F. Modeling of diffusion controlled drug delivery, J. Control. Release. 2012, 161, 351-362, http://doi.org/10.1016/j.jconrel.2011.10.006.

10. Yahya, I.; Atif, R.; Ahmed, L.; Eldeen, T,S.; Omara, A.; Eltayeb, M. Utilization of Solid Lipid Nanoparticles Loaded Anticancer Agents As Drug Delivery Systems for Controlled Release. Int. J. Eng. Appl. Sci. Technol. 2020, 4, 277-286, http://doi.org/10.33564/ijeast.2020.v04i10.053.

11. Jayanudin, Fahrurrozi, M.; Wirawan, Rochmadi, S.K. Preparation of Chitosan Microcapsules Containing Red Ginger Oleoresin Using Emulsion Crosslinking Method, J. Appl. Biomater. Funct. Mater., 2019, 17, 1-9, https://doi.org/10.1177/2280800018809917.

12. Babadi, F,E.; Yunus, R.; Soltani, S, M.; Shotipruk, A. Release Mechanisms and Kinetic Models of GypsumSulfur-Zeolite-Coated Urea Sealed with Microcrystalline Wax for Regulated Dissolution. ACS Omega, 2021, 6, 11144-11154, http://doi.org/10.1021/acsomega.0c04353.

13. García-González, C, A.; Sosnik, A.; Kalmár, J.; De Marco, I.; Erkey, C.; Concheiro, A.; Alvarez-Lorenzo, C. Aerogels in drug delivery: From design to application. J. Control. Release 2021, 332, 40-63, http://doi.org/10.1016/j.jconrel.2021.02.012.

14. Bakre, L.G.; Akinyele, E.; Bamiro, O.; Adeleye, O.; Kunle, O. Formulation and Evaluation of Sustained Release Ibuprofen Matrix Tablets Using Starch from Maize Genotypes as Polymer. Acta Marisiensis - Ser. Medica 2021, 67, 122-126, http://doi.org/10.2478/amma-2021-0018.

15. Nigusse, B.; Gebre-Mariam, T.; Belete, A. Design, development and optimization of sustained release floating, bioadhesive and swellable matrix tablet of ranitidine hydrochloride. PLoS One 2021, 16, 1-16, http://doi.org/10.1371/journal.pone.0253391. 